\title{
A FEIRA-LIVRE DE ALVORADA DE MINAS (MG): DINAMIZAÇÃO DA ECONOMIA LOCAL EM MUNICÍPIO ATINGIDO PELA MINERAÇÃO
}

\author{
Samanta Borges Pereira \\ Universidade Federal de Lavras, PPGA, Lavras, MG, Brasil \\ samantaborges81@gmail.com \\ Tayrine Parreira Brito \\ Universidade Federal de Itajubá, PPGDTecS, Itajubá, MG, Brasil \\ tairine prospe@hotmail.com \\ Viviane Guimarães Pereira \\ Universidade Federal de Itajubá, PPGDTecS, Itajubá, MG, Brasil \\ vgpereira@yahoo.com.br
}

\begin{abstract}
RESUMO
Este artigo discute a importância da feira-livre de Alvorada de Minas, em Minas Gerais, município que sofre com os impactos da atuação da mineradora Anglo American. Diante do quadro de fragilidades no qual a região se encontra, a feira pode representar um lugar de preservação das relações socioculturais, da autonomia do agricultor e do fortalecimento de seus laços sociais e do saber local. Nesse contexto, o objetivo deste trabalho é (re)conhecer a dinâmica de funcionamento da feira-livre existente no município estudado. Os questionamentos referem-se aos aspectos econômicos, representação na renda, gestão autônoma dos feirantes, movimentação da economia local e potencial para fortalecimento e expansão, além dos aspectos socioculturais, nas relações de pertencimento estabelecidas neste espaço. Metodologicamente, a pesquisa, de natureza qualitativa, utilizou-se de entrevistas, conversação e observação como instrumentos de coleta de dados, tendo por grupo de entrevistados feirantes, consumidores e comerciantes. Os resultados apontam para a predominância das mulheres neste espaço, a qualidade dos produtos da feira e a dinamização da economia local. Entretanto, o período recente de sua existência aponta para um espaço ainda não solidificado e para a necessidade de autonomia dos feirantes quanto à sua organização e gestão.
\end{abstract}

Palavras-chave: Agricultura familiar. Feira-livre. Geração de Renda. Comercialização. Espaço social.

\section{THE FAIR-FREE OF ALVORADA DE MINAS (MG): DYNAMIZATION OF THE LOCAL ECONOMY IN A COUNTY AFFECTED BY MINING}

\begin{abstract}
This paper discusses about the importance of the free fair of Alvorada de Minas, in Minas Gerais, county that suffers from the impacts of Anglo American mining company. In view of the fragility in which the region is, the fair can represent a place of preservation of sociocultural relations, autonomy of the farmer and the strengthening of social ties and local knowledge. In this context, the goal of this article is to (re) cognize the dynamics of the functioning of the free fair in the studied county. The questioning refers to economic aspects, representation of income, autonomous management of the fair participants, movement of the local economy and potential for strengthening and expansion, besides the socio-cultural aspects, in the relations of belonging established in this space. Methodologically, the qualitative research used interviews, conversation and observation as instruments of data collection, having as a group of interviewed people market participants, consumers and traders. The results point to the predominance of women in this space, the quality of the fair's products and the dynamism of the local economy. However, the recent period of its existence points to a space not yet solidified and to the need for autonomy of the fairgrounds in their organization and management.
\end{abstract}

Keywords: Family farming. Free Fair. Income Generation. Commercialization. Social space. 


\section{INTRODUÇÃO}

Este artigo é resultado parcial de pesquisa mais ampla que abrangeu o levantamento das potencialidades da agricultura familiar na região de Alvorada de Minas, Conceição do Mato Dentro e Dom Joaquim. A discussão proposta neste trabalho envolveu a importância da feira-livre de Alvorada de Minas, em Minas Gerais, município que sofre com os impactos da mineradora Anglo American. Os agricultores direta ou indiretamente afetados pelo empreendimento procuram formas de se reorganizar, na tentativa de minimizar os impactos da devastação sofrida pela prática da atividade minerária, tanto nos aspectos econômicos quanto socioambientais.

Tendo em vista que o processo de destruição inerente à implantação da mineradora em 2008 exige estratégias por parte das populações locais de minimização dos desmantelamentos sociais, econômicos e ambientais resultantes, o fortalecimento dos mercados locais pode contribuir para o enfrentamento dos problemas causados pelo empreendimento, que vem agravando suas condições de produção material e reprodução social.

Diante do quadro de fragilidades no qual a região se encontra, a feira pode representar um lugar de preservação das relações socioculturais, dos aspectos orgânicos ao ambiente rural, da autonomia do agricultor e do fortalecimento dos laços sociais e do saber local. Nesse contexto, o objetivo deste trabalho é (re)conhecer a dinâmica de funcionamento da feira-livre existente no município estudado. As abordagens referem-se aos aspectos econômicos - representação na renda, gestão autônoma dos feirantes, e potencial para fortalecimento e expansão, além dos aspectos socioculturais, nas relações de pertencimento estabelecidas neste espaço.

A importância da feira também se dá na oportunidade de abastecimento de produtos de características locais, além de baratos e saudáveis, garantindo a soberania e a segurança alimentar, pois o consumidor sabe onde e como os alimentos foram produzidos e a segurança é garantida no valor acessível, na diversidade e no uso quase que nulo de agrotóxicos, o que serve como um impulsionador da agricultura familiar e o desenvolvimento rural em bases sustentáveis.

Apesar de competirem com o comércio varejista, formado por mercados e supermercados, as feiras persistem e resistem, o que indica que além dos aspectos econômicos, elas trazem consigo aspectos de outras naturezas, como a social e a cultural.

O artigo está estruturado em cinco partes fundamentais: (1) Introdução, onde são apresentados os objetivos e a caracterização do município; (2) metodologia empregada, contando os caminhos percorridos na pesquisa; (3) contexto local, discorrendo sobre a presença da mineração no município; (4) discussão teórica sobre a produção camponesa e as feiras-; (5) caracterização da feira de Alvorada de Minas, apresentando sua estratégia de organização e comercialização, diversidade, qualidade e importância econômica. Encerra-se este trabalho apresentando Considerações finais e as referências utilizadas.

\section{METODOLOGIA}

A coleta de dados foi orientada pelo trabalho de Ribeiro (2007) sobre feiras-livres na região do Jequitinhonha que contribuíram para as políticas públicas de desenvolvimento rural na região. Para compreender o universo da feira de Alvorada de Minas utilizou-se de metodologia qualitativa, pautada na observação, entrevista e participação na feira e teve por tema 1) o feirante; 2) o espaço da feira; 3) o consumidor e 4) o comércio urbano. Assim, o grupo de entrevistados foi composto de feirantes, consumidores e comerciantes.

O feirante foi o centro da pesquisa, realizada através de roteiro semiestruturado, abordando os seguintes aspectos: (a) perfil do feirante: idade, sexo, escolaridade, formação da renda familiar e comunidade pertencente; (b) importância da feira: presença e frequência em feiras, importância da mesma na composição da renda familiar, formas de precificação, qualidade dos produtos ofertados, formas de negociação, variações nas vendas; (c) sistema de produção dos feirantes: diversidade da produção, a qualidade da água e a forma de produção; (d) o espaço da feira: infraestrutura e vantagens e desvantagens de participar deste espaço.

A pesquisa com os consumidores abordou a relação entre a feira e o abastecimento doméstico, a regularidade nas feiras e suas visões sobre a mesma. Para analisar os consumidores foi feita a distinção entre consumidores e frequentadores. Os frequentadores diferem dos consumidores, pois são aqueles que estão presentes na feira, mas não consomem naquele dia. $O$ frequentador de um dia

$\begin{array}{llllll}\text { Caminhos de Geografia } & \text { Uberlândia - MG } & \text { v. 19, n. } 68 & \text { Dez/2018 } & \text { p. 326-342 } & \text { Página } 327\end{array}$


pode vir a ser consumidor em outro dia e vice-versa. Nesta parte da pesquisa foram diferenciados os frequentadores - aqueles que vão com outros objetivos, como por exemplo, ver amigos, dar recados, negociar animais ou terrenos, etc. - e os consumidores - aqueles que vão comprar produtos. A soma de consumidores e frequentadores representa o total de pessoas que circulam pela feira.

A utilização dessa técnica apresenta algumas limitações. Consideram-se também como frequentadores as pessoas que consomem no próprio local, como alimentos prontos e bebidas, ou que consomem produtos pequenos como fumo e temperos e são colocados nos bolsos ao invés de utilizar sacolas. Nesses casos, essas pessoas não são contabilizadas como consumidores. Além disso, a contagem não contempla a flutuação da produção ao longo do mês, dado que no início do mês o fluxo é maior e decrescem na chegada do fim do mês. Portanto, os números apurados indicam um número médio, num período específico, tanto de consumidores quanto de frequentadores (RIBEIRO, 2007).

Em Alvorada de Minas a feira acontece em espaço aberto em todas as direções e a contagem foi feita através da observação, por ser pequeno o fluxo de consumidores. No dia da pesquisa, 20 de maio de 2016, foram contabilizados 65 consumidores e 28 frequentadores, totalizando 93 pessoas que circularam durante as 5 horas de funcionamento da feira.

A pesquisa no comércio local levantou informações sobre a relação entre a feira e o comércio urbano e a sistemática de compra dos feirantes. Foram realizadas entrevistas, através de roteiro semiestruturado, junto aos responsáveis pelos estabelecimentos comerciais, principalmente aqueles no entorno do espaço da feira, para compreender o impacto que ela produz no movimento do comércio local. Foram entrevistados os responsáveis por estabelecimentos do tipo armazém e supermercado, comércio de roupas, sapatos, tecidos, farmácias, lojas de material de construção, padarias, lanchonetes.

As análises foram realizadas a partir do entrelaçamento dos resultados com a teoria privilegiada, intercalando os dados empíricos quanto aos aspectos econômicos, sociais, culturais e identitários com os princípios conceituais que compreendem a feira enquanto espaço plural.

Foram priorizadas importantes pesquisas sobre as feiras-livres como as de Angulo (2003) e a feira de Turmalina (MG), Sacco dos Anjos et al. (2005) e a feira de Pelotas (RS), Morais e Araújo (2006) e a feira de Caicó (RN), Ribeiro (2007) e as feiras do Jequitinhonha (MG), Santos et al. (2014) e a feira de Santo Estevão (BA), Borges et al. (2016) e a feira de Marmeleiro (PR), Paulino et al. (2017) e a feira de Couto Magalhães (MG).

Enquanto circuitos curtos de comercialização, foram utilizadas as pesquisas de Ferrari (2011) e Schneider e Ferrari (2015); sobre as feiras enquanto lugar de interação e reprodução social, as análises pautaram-se em Braudel (2009); Godoy e Anjos (2007), Carpegeani e Rezende Filho (2009); Lovatto et al. (2008) e Pra et al. (2016) contribuíram na compreensão sobre a organização social; Anacleto et al. (2016) ajudaram nas elaborações sobre a participação feminina na feira. Outros autores contribuíram com aspectos mais gerais ou mais específicos referentes à dinâmica da feira.

\section{O CONTEXTO LOCAL}

Alvorada de Minas possui 3.546 habitantes e $374,01 \mathrm{~km}^{2}$, com uma densidade demográfica de 9,48 habitantes por $\mathrm{km}^{2}$. O total da população rural é de 2.096 habitantes, o que corresponde a $59 \%$ da população total (IBGE, 2010). Alvorada de Minas pertenceu ao município do Serro até 1962 e atualmente é constituído de dois distritos. A povoação originária surgiu a partir dos bandeirantes à procura de ouro e pedras preciosas às margens do Rio do Peixe. A mineração atraiu novos moradores que depois voltaram sua atenção às lavouras e criação de gado, desenvolvendo-se o povoamento (IBGE, 2010).

A chegada da mineradora em 2008, com a incursão da Anglo American e a construção do maior mineroduto do mundo, provocou mudanças estruturais na agricultura familiar do município e região. Embora a maior parte do empreendimento minerário esteja sediada em Conceição do Mato Dentro, município vizinho (Figura 1), a população de Alvorada de Minas vem sofrendo intensamente os impactos desta atividade. 
Figura 1: Localização da mina de extração mineral da Anglo American.

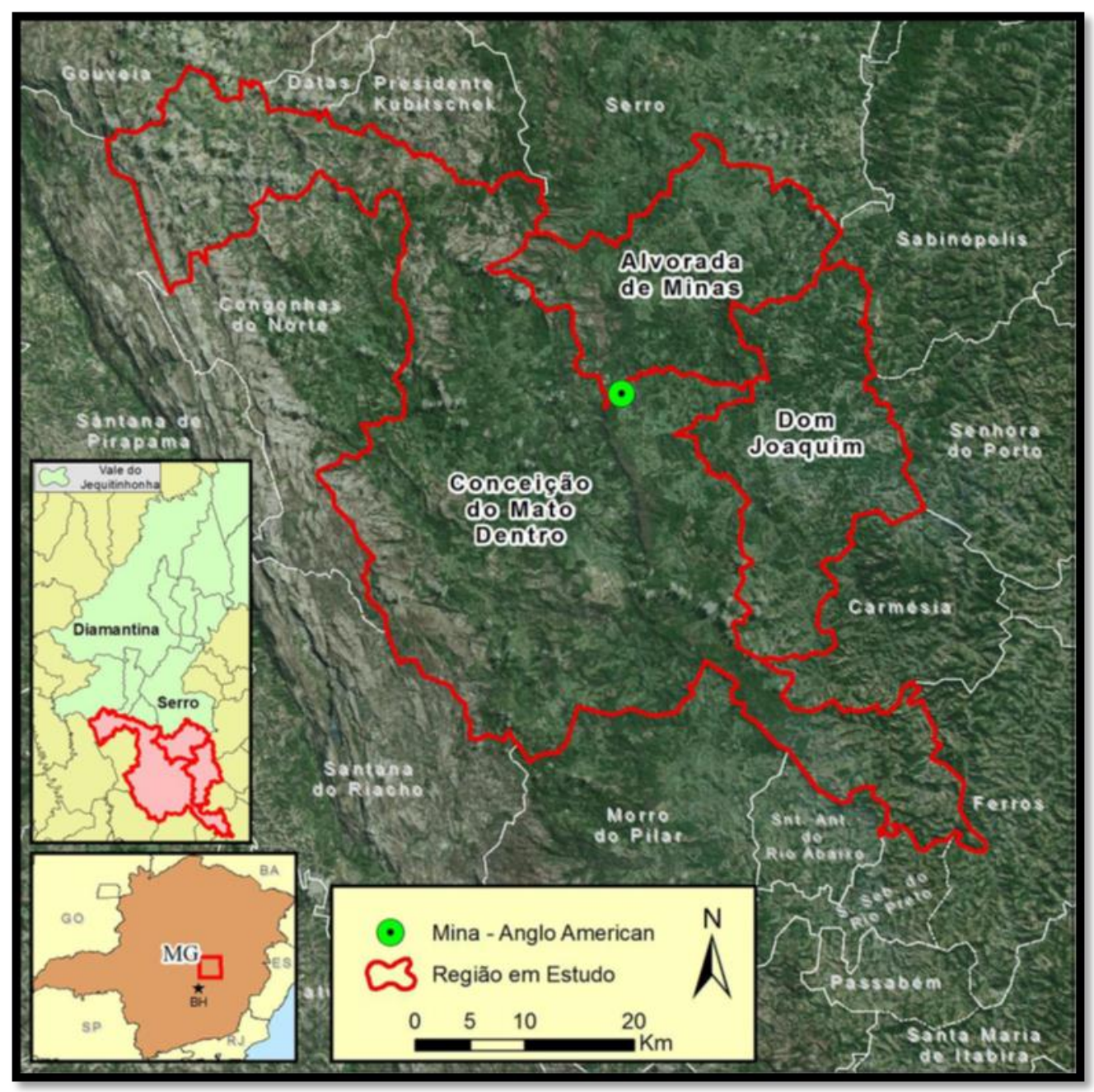

Fonte: elaborada pelos autores

Este projeto de extração do minério de ferro denominado Projeto Minas-Rio, é um complexo de extração mineral composto por três grandes partes: a extração, a logística e a exportação. A extração acontece em local de divisa municipal, entre os municípios de Conceição do Mato Dentro e Alvorada de Minas, realizada em uma mina que abrange as Serras do Sapo e da Ferrugem, em Conceição do Mato Dentro e, ao lado, existe uma planta de beneficiamento no município de Alvorada de Minas, além de uma barragem de rejeitos, somando uma área de aproximadamente $30 \mathrm{~km}^{2}$ (Figura 2).

O transporte é realizado via mineroduto, o maior do mundo, com extensão de $525 \mathrm{~km}$, saindo de Dom Joaquim e passando por 33 municípios, atravessando o estado de Minas Gerais e Rio de Janeiro, até chegar ao Porto do Açu, em São João da Barra - RJ. É pelo Porto do Açu, que os minérios são exportados, principalmente para China e Europa (PEREIRA et al., 2013; BARCELOS, 2013).

A capacidade de produção do Projeto Minas-Rio é de 26,6 milhões de toneladas de minério de ferro por ano - projeto complexo e grandioso, que foi orçado em US\$ 3 bilhões. A princípio, o projeto era da MMX Mineração e Metálicos S.A. de propriedade do empresário Eike Batista, empresa responsável pela elaboração do projeto em parceria com os governos dos estados de Minas Gerais e Rio de Janeiro. Antes da implantação, o projeto foi vendido para a empresa transnacional Anglo American, fundada na África do Sul em 1917 por Sir Ernest Oppenheimer, com sede atual em Londres. O grupo atua há décadas na extração de minérios, principalmente na África do Sul, na Austrália, no Canadá e no Brasil, presente desde 1973. Em 2007, a empresa comprou o Projeto Minas-Rio e criou a Anglo Ferrous Brazil, unidade de negócios sediada no país, voltada para extração, beneficiamento e exportação do minério de ferro (BARCELOS, 2013; ANGLO AMERICAN, 2014). 
Figura 2: Planta industrial minerária e barragem de rejeitos em Conceição do Mato do Dentro e Alvorada de Minas - MG, aproximadamente $30 \mathrm{~km}^{2}$.

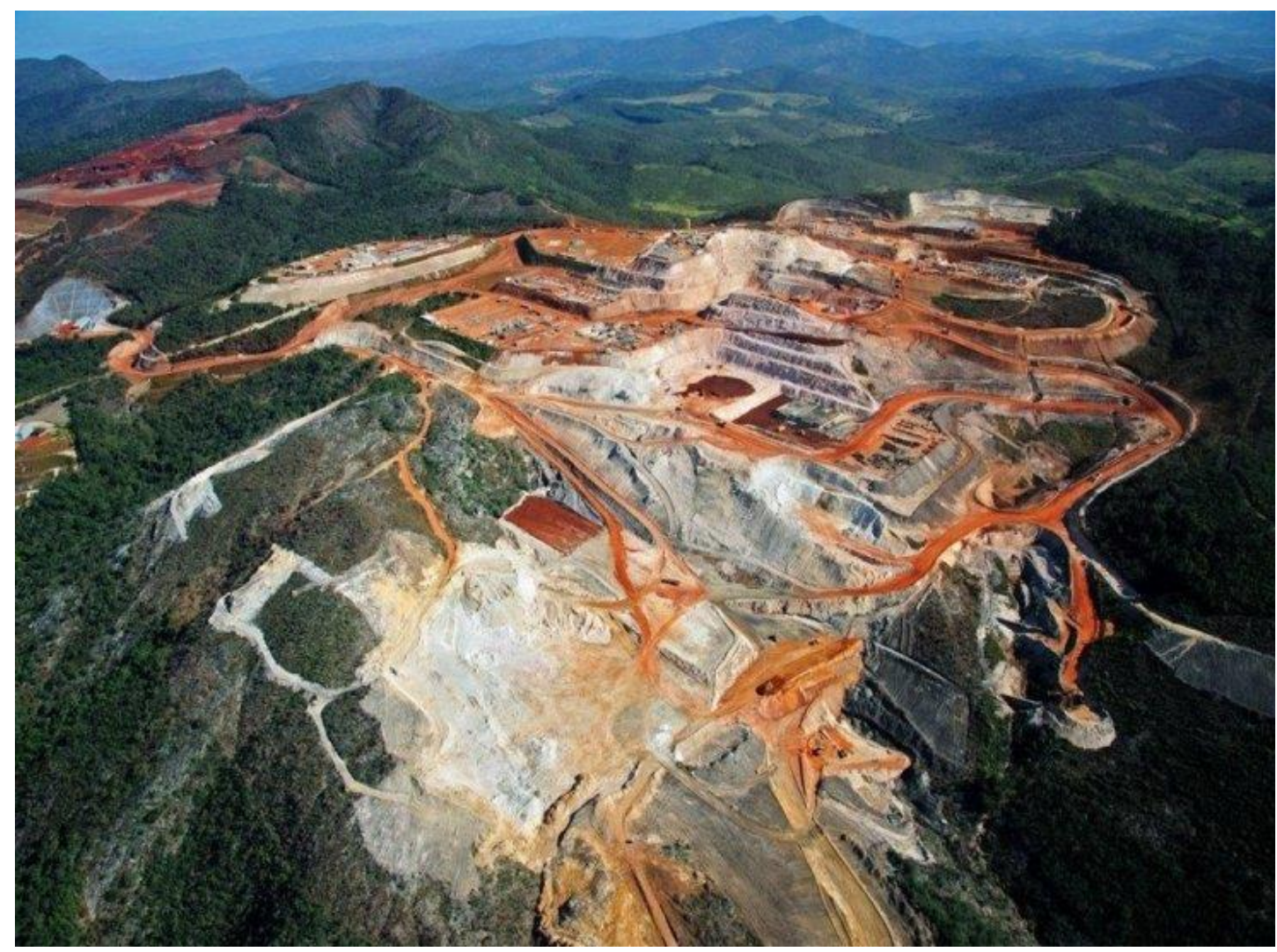

Fonte: Coordenadoria Regional das Promotorias de Justiça do Meio Ambiente da Bacia do Rio Grande (2012)

Antes de o empreendimento entrar em funcionamento, a Secretaria de Estado de Meio Ambiente e Desenvolvimento Sustentável (SISEMA - MG) emitiu um parecer técnico sobre o Estudo de Impacto Ambiental (EIA) do empreendimento, alertando que cursos d'água poderiam ser extintos e que havia famílias dependentes desta água (PEREIRA et al., 2013). Hoje, a escassez de água seja pela contaminação ou pela diminuição da vazão de nascentes e córregos, está presente nas vozes das comunidades rurais e também documentada nos trabalhos de diversos autores (PEREIRA et al., 2016; BELLEZE, 2017; VIEIRA, 2017).

Belleze (2017) levantou uma série de impactos identificados pelos agricultores familiares de Alvorada de Minas além da escassez de água, como: os prejuízos na produção, a privatização dos recursos, o esvaziamento do campo e a violação dos direitos (negociações abusivas). Estes impactos interferiram diretamente na capacidade produtiva das famílias agricultoras.

As comunidades rurais de Descoberto e Bom Jesus, no município de Alvorada de Minas, ficaram cercadas pelas áreas de proteção ambiental implantadas pela Anglo American como medida de compensação ambiental. Antes, essas áreas eram utilizadas pelas famílias da comunidade como uma extensão de suas casas, de onde extraiam lenha, colhiam frutas, plantavam entre as árvores e plantavam também como meeiros dos proprietários das terras que eram privadas, em uma relação harmônica (BELLEZE, 2017).

Alvorada de Minas se destaca na produção leiteira e na elaboração artesanal do famoso "Queijo do Serro", patrimônio cultural nacional (IPHAN, 2006). O regime hídrico influi diretamente sobre a quantidade e a qualidade do leite (SANTOS, 2011) o que também resulta sobre a qualidade dos queijos.

A prática da pecuária nos estabelecimentos da agricultura familiar no município alcança $75 \%$ das unidades familiares. Há uma forte ligação entre a atividade agrícola e a pecuária, tendo em vista que suas lavouras ou têm diminuído ou passam a existir apenas para abastecer o gado, principalmente lavoura de cana e milho. Apesar do destaque para a pecuária leiteira, não se pode dizer que os

$\begin{array}{llllll}\text { Caminhos de Geografia } & \text { Uberlândia - MG } & \text { v. 19, n. } 68 & \text { Dez/2018 } & \text { p. 326-342 } & \text { Página } 330\end{array}$


agricultores abriram mão da diversificação das atividades como estratégia de sobrevivência, pois esta "vocação" para a diversidade é intrínseca à categoria dos agricultores familiares/camponeses. As principais lavouras cultivadas na região estão distribuídas em roças de cana, milho, feijão, mandioca e café, que tem como destino o autoconsumo familiar, mas também o comércio e as trocas comunitárias. A cana e o milho têm como destino certo o trato dos animais (PEREIRA et al., 2016).

Os quintais das unidades familiares - lugar do pomar, horta, chiqueiro, galinheiro - são o resultado do trabalho na formação do terreno familiar, e são importantes fontes de segurança alimentar das famílias. A horta e o pomar possuem produtos variados, mas não com a mesma abundância em todas as regiões. Os pomares são os espaços menos formados pelo trabalho da família, apresentamse mais diluídos, pois algumas das árvores frutíferas estão espalhadas dentro e fora dos terrenos familiares, e são vistos como algo que a natureza oferece, sem que alguém se preocupe em plantar. Dentre as plantadas nos quintais e aquelas que a natureza oferece existe uma grande variedade: banana, laranja, acerola, manga, mexerica, limão, mamão e goiaba (PEREIRA et al., 2016).

As hortas não aparecem durante todo o ano, seja pelo excesso ou pela falta d'água: no tempo das águas não há intenção de plantar, pois o tempo não ajuda e as hortaliças costumam "melar"; no tempo da seca, que seria o melhor período para se plantar, há atualmente a dificuldade de levar água até os quintais. Quando a água começa a faltar, o que primeiro se diminui é o "aguar" das hortas, priorizando o uso da água para dentro de casa, no fazer comida, limpar a casa e banhar-se. Ainda assim, algumas famílias comercializam hortaliças na sede do município, de porta em porta, na feira local e também entregam para o PNAE - Programa Nacional de Alimentação Escolar (PEREIRA et al., 2016).

A criação de pequenos animais, como galinhas, porcos e, em poucos casos, peixes, são voltadas para o autoconsumo familiar, mas também são comercializadas galinhas, ovos, porcos, e também trocados dentro das próprias comunidades. Esta é uma característica importante do campesinato: quando há excedentes, faz-se a troca direta entre os membros da própria comunidade, isso demonstra a forte sociabilidade existente no campesinato (PEREIRA et al., 2016).

Após a chegada da mineradora, muitas famílias reduziram expressivamente a produção de queijos, consequência da escassez de água provocada pela presença da mineradora. Além disso, muitos agricultores deixaram os trabalhos da roça para irem trabalhar na atividade minerária (PEREIRA et al., 2016).

\section{A AUTONOMIA PRODUTIVA CAMPONESA E A FEIRA-LIVRE: GERAÇÃO DE RENDA E FORTALECIMENTO DE IDENTIDADES}

$\mathrm{Na}$ agricultura camponesa está a maior parte da população agrícola do mundo e sua contribuição para a produção de alimentos, geração de emprego e renda, sustentabilidade e desenvolvimento é enorme. Segundo Ploeg (2009) existe uma "condição camponesa" e a agricultura camponesa, ou modo de produção camponês estão imersos nessa condição. A co-produção, ou seja, o processo de produção agrícola, é um dos elementos mais importantes para se definir o campesinato e diz respeito à interação e transformação mútua constantes entre o homem e a natureza viva. A co-produção retroalimenta e fortalece a base de recursos, melhorando o próprio processo de co-produção, ou seja, os recursos não são apenas convertidos em bens e serviços, mas também reproduzidos como recursos. São expressões da co-produção: a agricultura, a criação de animais, a horticultura, a silvicultura, a caça e a pesca, a transformação dos produtos obtidos em outros mais elaborados, o turismo rural.

$\mathrm{Na}$ medida em que a co-produção retroalimenta e melhora seu próprio processo de co-produção através de melhorias qualitativas (ex: tornando a terra mais fértil, selecionando melhores mudas, cruzando vacas mais produtivas, construindo melhores instalações, etc.), ela contribui para a ampliação da autonomia, que é uma luta permanente do campesinato. Essa luta pela autonomia está fortemente ligada às relações com o mundo exterior, ou seja, padrões de relações mercantis como formas que permitem a autonomia, e neste caso, a desconfiança é tanto um reflexo de ambientes hostis como uma resposta a eles (PLOEG, 2009).

A agricultura camponesa é menos dependente do mercado para o acesso a insumos e outros meios de produção, pois para ela, esses meios e insumos são parte integrante do estoque disponível de capital ecológico, e isso garante sua autonomia, pois a extensão e consolidação da base de recursos também são consideradas como criação de patrimônio. A co-produção não só garante a

$\begin{array}{llllll}\text { Caminhos de Geografia } & \text { Uberlândia - MG } & \text { v. 19, n. } 68 & \text { Dez/2018 } & \text { p. 326-342 } & \text { Página } 331\end{array}$


sobrevivência como também fortalece a base de recursos. A condição camponesa flui para uma especificação do modo camponês de fazer agricultura (PLOEG, 2009).

Diante da capacidade que o campesinato tem de se articular com a economia capitalista mantendo sua autonomia de gestão da unidade produtiva, e mantendo a sua capacidade produtiva fundada no uso racional dos recursos naturais, através de autonomia produtiva e de gestão indicados por Ploeg (2009), se exprime o contexto das feiras livres. A feira-livre pode representar uma possibilidade de geração de renda para as famílias que estão sendo atingidas pela mineração, caracterizada como um tipo de mercado alinhado com o desenvolvimento territorial que fomenta a organização local e valoriza os costumes e cultura regionais.

O intenso debate pela necessidade de consolidação e do alcance das políticas públicas direcionadas aos agricultores familiares inflama a busca por mercados que permitam à família agricultora, além da venda de seu cultivo, contribuir com o desenvolvimento rural, por meio de um ciclo de geração de renda, qualidade de vida, preservação da cultura local, sustentabilidade social e ambiental.

Segundo Schneider e Ferrari (2015), as cadeias curtas, que se dão no encurtamento da distância entre produtores e consumidores, se apresentam como opções em três dimensões: (1) espaciais, ao abreviar as distâncias que os alimentos percorrem entre a produção e o consumo; (2) social, ao gerar contato face a face entre produtores e consumidores, que resultam em confiança e integração na cadeia; e, (3) econômica, criando mercados locais para a produção.

Neste sentindo, as feiras livres são mercados socialmente construídos, denominados de mercados imersos. Nestes mercados existe uma intensa interação de diferentes atores que buscam "construir formas mais autônomas e diferenciadas de transações econômicas na produção e no consumo de alimentos" (CASSOL et al., 2016, p. 318).

Para Ferrari (2011), uma característica relevante das cadeias agroalimentares curtas é a habilidade para ressocializar ou reespacializar o alimento, possibilitando o julgamento de valor pelo consumidor. Segundo o autor, espera-se que os mercados de venda direta possibilitem preços justos, a reconquista do controle sobre as vendas pelo agricultor e a participação do consumidor na avaliação da qualidade dos produtos.

As feiras-livres apresentam-se como um importante canal de comercialização para a agricultura familiar, de relevância irrefutável, em que apresentam uma verdadeira teia de relações. São espaços públicos e lugares de interação onde diferentes racionalidades, para além da econômica, tais como a comunitária, a religiosa, a familiar e a societária se influenciam mutuamente, com imenso potencial para a reprodução social (ANGULO, 2003; GODOY e ANJOS, 2007; RIBEIRO, 2007; CARPEGEANI e REZENDE FILHO, 2009).

A agricultura familiar corresponde a $84 \%$ dos estabelecimentos agropecuários brasileiros, produzindo grande parte dos alimentos que compõe as refeições diárias, como a mandioca (87\%), o feijão (70\%), a carne suína (59\%), o leite (58\%), carne de aves (50\%) e o milho (46\%) (GABOARDI JÚNIOR, 2013; SANTOS et al., 2014),

É essencial que projetos de desenvolvimento municipal e regional tenham suas bases na agricultura familiar. Para Santos et al. (2014, p. 02).

[...] uma condição de sobrevida para a economia de um grande número de municípios brasileiros, é o desenvolvimento com distribuição de renda no setor rural que viabiliza e sustenta o desenvolvimento do setor urbano, desencadeando o desenvolvimento regional.

A feira não abrange apenas a agricultura familiar, mas também os consumidores e a população urbana como um todo, gerando receitas, dinamizando os municípios, criando e colocando em circulação recursos que alimentam a população urbana, contribuindo para a soberania alimentar, beneficiando agricultores, comércio e consumidores (RIBEIRO, 2007).

A agricultura familiar que reconhecidamente cumpre um papel fundamental no fornecimento de alimentos (ABRAMOVAY, 1992), é uma via para garantir a segurança alimentar da população em geral (RIBEIRO, 2007) e de sua família, já que caso o mercado não lhe seja adequado, a alimentação da sua família não estará comprometida (ABRAMOVAY, 1992).

$\begin{array}{llllll}\text { Caminhos de Geografia } & \text { Uberlândia - MG } & \text { v. 19, n. } 68 & \text { Dez/2018 } & \text { p. 326-342 } & \text { Página } 332\end{array}$


Ao estudar as feiras-livres do Jequitinhonha, em Minas Gerais, Ribeiro (2007) aponta que seriam estas umas das instituições mais sólidas no território mineiro. $O$ autor constata que os agricultores feirantes são beneficiados porque vendem uma produção que não entraria em outros mercados, já que sua pauta produtiva é muito associada à cultura alimentar local.

Os apontamentos de Ribeiro (2007) vão ao encontro do que Cassol et al. (2016, p. 320) compreendem sobre os mercados imersos:

\begin{abstract}
Segundo esta perspectiva, os mercados imersos são construídos sobre um conjunto de regras e formas de governança que permitem que os produtos ofertados por pequenos agricultores possam concorrer com os modos industriais de produção e os mercados convencionais, na medida em que são capazes de conferir distintividade aos produtos e criar novos padrões de governança.
\end{abstract}

Fato este relacionado às peculiaridades produtivas da agricultura familiar, ligada à cultura e os costumes regionais, onde não existe um padrão, diferenciando-se do que se encontra nos mercados convencionais.

De acordo com Ploeg (2008) mais de $80 \%$ da produção mundial de alimentos não passa pelo processamento da grande indústria, isto é, a distribuição é realizada em vendas diretas, através de circuitos curtos, confirmando assim, a importância das feiras livres.

Angulo (2003), ao estudar a feira-livre de Turmalina, no Vale do Jequitinhonha, afirma que ela não se constitui um sistema socioeconômico homogêneo, pois depende de vários fatores sociais e produtivos (terra fértil, disponibilidade de água, mão de obra disponível) que vão, consequentemente, influenciar na sua dinâmica.

Desta forma, a feira-livre de Alvorada de Minas, objeto desta pesquisa, possui uma representação ainda maior, pois passa a ser também uma alternativa para a autonomia das famílias agricultoras que vê sua região destruída - enquanto natureza, relações sociais, culturais e econômicas - pela ação da mineradora.

\title{
A FEIRA-LIVRE DE ALVORADA DE MINAS
}

As feiras podem e devem ser um recurso utilizado para o desenvolvimento da economia local, por meio do abastecimento de alimentos frescos, produtos especiais e produtos com identidade, além de ser espaço de encontros sociais e de articulação política (SANTOS et al., 2014).

$\mathrm{Na}$ pesquisa realizada por Conceição et al. (2016) sobre a comercialização da produção dos assentamentos da fronteira Brasil-Bolívia, a feira livre foi considerada um dos principais mercados para as famílias assentadas, pois além de oportunizar a venda direta, excluindo a presença do atravessador, ainda garante a autonomia na oferta de acordo com a sazonalidade da produção.

Vale ressaltar que a autonomia abordada neste texto não diz respeito somente aos aspectos econômicos da autonomia gerada a partir da renda adquirida na feira, mas da liberdade de produzir e comercializar o que por alguma circunstância (social, cultural, ambiental) se escolhe. Diante da importância das feiras-livres, analisaremos a dinâmica de funcionamento da feira de Alvorada de Minas. As investigações abarcaram a organização e o espaço da feira, o feirante e a importância da feira enquanto geração de renda, o consumidor e o comércio local.

\section{A ORGANIZAÇÃO E O ESPAÇO DA FEIRA}

A feira-livre de Alvorada de Minas existe desde 2013 e sua realização é semanal, às sextas-feiras pela manhã, na praça central, corroborando a definição de Mascarenhas e Dolzani (2008) quanto à periodicidade e modalidade. Para os autores, a feira-livre no Brasil

[...] constitui modalidade de mercado varejista ao ar-livre, de periodicidade semanal, organizada como serviço de utilidade pública pela municipalidade e voltada para a distribuição local de gêneros alimentícios e produtos básicos (MASCARENHAS e DOLZANI, 2008, p. 75).

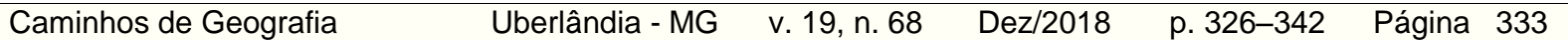


Para Guerreiro (2008), a feira é um lugar de recuperação e valorização das tradições. Em Alvorada de Minas, por ser recente, este espaço ainda não se configura desta forma.

Os feirantes acreditam que aos sábados o movimento poderia ser mais intenso, como acontece nas feiras de Santo Estevão/BA (SANTOS et al., 2014), Couto de Magalhães de Minas/MG (PAULINO et al., 2017), Conceição do Mato Dentro/MG (PEREIRA et al., 2017), Marmeleiro/PR (BORGES et al., 2016).

Segundo os entrevistados, haveria mais movimento devido à presença de pessoas de fora da cidade. Além disso, já tiveram a experiência de realizar a feira aos sábados e, segundo os entrevistados, o movimento era mais intenso. Porém, neste dia faltaria o suporte do poder público municipal no transporte dos feirantes e no fornecimento da estrutura.

A organização da feira é realizada pela prefeitura, através da Secretaria de Agricultura, com o apoio da EMATER. Há um regimento que formaliza a organização da feira e a prefeitura oferece o transporte, as barracas e sua montagem e desmontagem e o espaço para guarda-las, além de ajuda na apresentação e exposição dos produtos.

O apoio do poder público é fundamental para a solidificação da feira, principalmente nos primeiros anos. Segundo Ribeiro et al .2003) o transporte dos feirantes e de seus produtos é fator imprescindível para ampliar o número de agricultores beneficiados pela comercialização nas feiraslivres realizadas no meio urbano.

Por receberem o suporte da prefeitura, a realização da feira aos sábados torna-se mais difícil já que os servidores não trabalham neste dia. Ressalta-se a relevância da participação do poder público, mas a importância de tornar o feirante independente deste e outras instituições e autônomo quanto à organização deste espaço.

A autonomia evita que, na ausência dos apoios, a realização da feira permaneça. Um bom exemplo é a feira de Conceição do Mato Dentro, existente há mais de 50 anos. Realizada no Mercado Municipal, a feira de Conceição do Mato Dentro configura-se como um espaço de trocas comerciais e sociais. Os feirantes possuem sentimento de pertencimento, passado por gerações, além de serem auto organizados (PEREIRA et al., 2017).

Apesar do apoio da prefeitura, dos 15 agricultores cadastrados somente 04 estavam participando da feira no momento da pesquisa, o que se deveu à falta de produção decorrente da falta de água. Apesar da carência de chuva nos últimos anos em todo o país (MARENGO et al, 2015), a falta de água em Alvorada de Minas está estreitamente relacionada à atividade minerária, que tem limitado as estratégias de produção das famílias (BELLEZE, 2017).

Os dados de pesquisa mostraram variações na oferta de produtos, influenciadas pelas intempéries climáticas, apresentando aspectos significativos de volubilidade e instabilidade quanto à presença de agricultores e sua produção. As feiras são consideradas mercados inseguros devido às intempéries da natureza (e à oscilação dos preços), riscos que são considerados por Buainan e Souza Filho (2006) passíveis de acontecer também nos mercados corporativos e/ou institucionais.

Quanto ao local de realização, os feirantes consideram "o melhor lugar de Alvorada para a feira", com bastante fluxo de pessoas e boa visibilidade. A região central, apesar de se diferenciar do centro das grandes cidades, ainda é onde se concentra o comércio local, serviços públicos oferecidos à população, igrejas, escolas, etc.

Quanto ao lugar que ocupam na feira, os feirantes escolhem arbitrariamente, ao chegar no local pela manhã. Como são poucas bancas e todas ao lado uma da outra, não há impedimento ou conflito na escolha de lugares.

Os feirantes sugerem algumas melhorias de estrutura como uma cobertura que possa protegê-los - e proteger os produtos - das intempéries climáticas, banheiros e pias para uso exclusivo dos feirantes e a limpeza da praça antes da realização da feira, pois há fezes de animais próximas às bancas.

A falta de cobertura do espaço onde ocorre a feira é uma condição recorrente entre as feiras no Brasil, especificamente nas feiras mais novas, já que as feiras antigas geralmente ocorrem em locais cobertos e fechados. Em Couto Magalhães de Minas a situação já foi semelhante ao que ocorre em Alvorada de Minas, quando no início, a feira era realizada ao ar-livre na praça central da cidade, mas atualmente, a feira conta com um local fixo e coberto (PAULINO et al, 2017). 
Embora as feiras-livres tenham importante papel na dinamização da economia local, para a geração de trabalho e renda no campo e para oferta de alimentos frescos e saudáveis para populações urbanas, em Alvorada de Minas ela ainda se faz como espaço pouco frequentado, tanto pelos agricultores quanto pela população local.

\section{O FEIRANTE}

Quanto à caracterização do feirante de Alvorada de Minas, trata-se de acordo com a classificação de Ploeg (2008) de agricultores camponeses, pouco ou nada integrados ao mercado. Destaca-se a predominância feminina e o protagonismo das mulheres na atividade de comercialização dos produtos de suas unidades familiares na feira. Conceição et al. (2016) também observaram essa predominância feminina nas feiras livres dos municípios de Corumbá e Ladário - MS. De acordo com Anacleto et al. (2016, p.2),

[...] as feiras-livres desenharam um novo panorama nas atividades relacionadas ao contexto rural, dado que possibilitou além de escoar a produção, a criação de um cenário onde as mulheres rurais assumiram importante papel no protagonismo das famílias.

Essa reflexão visa contribuir com a luta da mulher no espaço rural. A compreensão mais ampla sobre predomínio da mulher na feira precisa de aprofundamentos de pesquisa. Contudo, esses apontamentos mostram que este espaço pode se configurar como uma possibilidade de autonomia para as mulheres, ratificando o seu importante papel no desenvolvimento rural.

Quanto às comunidades de origem dos feirantes, eles pertencem à Lapinha, Quilombo Cachoeira, Ribeirão Santana e Fazenda da Ponte, estando distantes da feira de $4 \mathrm{~km}$ a $18 \mathrm{~km}$. Os atuais feirantes participam há mais de 18 meses, sendo que alguns estão desde o seu início de funcionamento. Para iniciarem a participação não houve necessidade de recorrerem a nenhum recurso externo, pois já tinham produção suficiente para vender.

Com relação à diversidade da produção, os feirantes lidam com lavoura, horta e pomar, com produção variada em: feijão, milho, café, jiló, quiabo, mandioca, alface, couve, cebolinha, inhame, berinjela, cenoura, urucum, tempero, laranja, limão, mamão e banana, além dos produtos processados: goiabada, requeijão, fubá e farinha. Há também os produtos de origem animal, como o frango caipira, o mel e o leite.

Para o plantio usam o esterco, sementes próprias e sementes compradas. Apenas um entrevistado informou usar adubo comprado. Os feirantes dizem não usar nenhum tipo de veneno em suas produções. Um dos diferenciais das feiras - e uma possível vantagem estratégica onde o agricultor familiar é o protagonista - é a qualidade dos alimentos e a associação de seus produtos à tradição, à natureza, ao artesanal e ao local (SCHNEIDER e FERRARI, 2015).

Não há significativas variações de produtos durante o ano, variando somente a quantidade ofertada, de acordo com a época de cada produto. Vende-se mais de janeiro a junho já que depois deste período, há muita oferta dos mesmos produtos por todos os feirantes.

A decisão sobre quantidade, variedade e qualidade dos produtos a serem levados para a feira baseia-se:(1) no que está disponível no dia; (2) o que dá tempo de colher;(3) produtos não deformados; (4) frescos/naturais;(5) vistosos, trazendo um pouco de tudo, em quantidades que não irão sobrar. Há um zelo pelos produtos que serão levados para a feira, pois é isso que garantirá a venda.

A estratégia para a precificação dos produtos envolve: (i) Tabela de preços baseada nos gastos com a produção; (ii) consulta dos preços praticados no "sacolão", colocando abaixo deste; (iii) prática de diminuir os preços no final da feira, para evitar a perda, principalmente dos produtos mais perecíveis; (iv) variação de preços durante o ano de acordo com a demanda e com a época dos produtos: 0 excesso de oferta faz com que os feirantes diminuam os preços.

Percebe-se que os feirantes desenvolveram estratégias de minimização de perdas e/ou desperdícios das sobras, mostrando-se mais eficientes do que as centrais de abastecimento atacadista, que 
quantificam perdas significativas, conforme estudos de Belik et al. (2012) que aborda estratégias para redução de desperdícios de alimentos.

A renda advinda da feira de Alvorada de Minas representa toda a renda pessoal para $25 \%$ dos entrevistados; metade da renda pessoal para $50 \%$ dos entrevistados e menos da metade da renda pessoal para $25 \%$ dos entrevistados.

Para a maioria dos feirantes a renda da feira representa um incremento financeiro ao orçamento familiar. A pesquisa de Ribeiro et al. (2005) em Minas Nova/MG mostrou que para a maioria dos entrevistados a feira era a única fonte de renda ou representava mais da metade da renda familiar.

A comercialização da agricultura familiar baseada em relacionamento individual com intermediários dotados de infraestrutura de comercialização é responsável pela baixa renda dessa atividade (GOMES JUNIOR et al., 2008). A produção da feira de Alvorada de Minas advinda fortemente do trabalho da família e sem a presença de intermediários, resulta em autonomia e independência do agricultor, melhorando sua renda.

Os feirantes e seus familiares também realizam outras atividades remuneradas como: dias de serviço (colheita, capina), artesanato, venda de queijo, doces e quitandas por encomenda, venda de porco e galinha em casa, ou ainda na prefeitura, na mineradora Anglo American, no Centro de Referência de Assistência Social (CRAS) municipal e realizando vendas no município do Serro, o que reforça a diversidade na composição da renda destes agricultores.

A renda adquirida na feira é usada para os gastos de casa e para investir na produção, além de cuidados com a saúde. Essa renda tem representado um importante papel de contribuição no orçamento familiar dos feirantes de Alvorada de Minas.

\section{O CONSUMIDOR}

Os consumidores são fixos e variáveis e mesmo quando variáveis, são conhecidos dos feirantes. Quase todos os feirantes informaram vender à vista, mas vendem fiado para algum conhecido que precise. Apenas um feirante informou que as vendas a crédito sobressaem.

O público frequentador é predominantemente feminino, assíduo e seus gastos variam de $R \$ 10,00$ a $\mathrm{R} \$ 40,00$ por consumidor, com média em torno de $\mathrm{R} \$ 25,00$. Brandão et al. (2012, p. 691) salientaram que "existem poucas informações a respeito da importância das feiras no cotidiano do consumidor que compra hortaliças" e que este público escolhe comprar na feira por valorizar a qualidade e a tradição dos alimentos, não sendo os preços um critério de escolha.

Os gastos inferiores validam as afirmações de Sacco dos Anjos et al. (2005), quanto a capacidade da feira em propiciar à comunidade a oferta de produtos essenciais a um preço mais acessível. Por outro lado, os gastos superiores apoiam-se nas considerações de Ribeiro et al. (2003) sobre a busca de mercados específicos, baseados na agregação de valor aos bens agrícolas, cuja produção esteja fundamentada em diferenciais qualitativos de natureza social, ambiental ou cultural, consolidados por uma demanda segmentada, composta de consumidores dispostos a pagar um preço também diferenciado.

Os consumidores da feira são, prioritariamente, os moradores de Alvorada (da cidade), os que moram perto, os que estão na cidade para fazer alguma coisa, moradores de Belo Horizonte que são de Alvorada de Minas e, esporadicamente, turistas.

O fortalecimento da feira pela via do turismo vem atender às afirmações de Carpegeani e Rezende Filho (2009) sobre a dinamização da feira pelo poder público pela via da valorização do lugar, fomentando a identidade cultural. A presença do turista pode ser explicada pela imagem simbólica em relação à natureza e mundo rural que revelam algumas feiras (AGUILAR, 2004), simbolismo que desperta sedução enquanto apelo turístico de identidade local.

Consome-se de tudo um pouco, tendo como o forte da feira as hortaliças (verduras em geral, jiló, couve, alface, couve-flor, rúcula, abobrinha e espinafre) e frutas (laranja e banana). Existem os produtos que são encontrados somente na feira, como a couve-flor, o doce, pãozinho, mel e requeijão. Percebe-se que os consumidores valorizam o caráter local e cultural da feira. Há atribuição de valor ao produto advindo da roça quando dizem que só encontram alface e verdura boa sem remédio, na feira. Com menos frequência, mas presente nas compras, está a galinha caipira e o artesanato.

\begin{tabular}{llllll}
\hline Caminhos de Geografia & Uberlândia - MG & v. 19, n. 68 & Dez/2018 & p. 326-342 & Página 336
\end{tabular}


No contexto atual, em que permanece a questão da segurança alimentar e nutricional, a importância das feiras adquire visibilidade em relação à disponibilidade e garantia de acesso a alimentos social e culturalmente referenciados (SACCO DOS ANJOS et al., 2005) já que sua pauta produtiva é muito associada à cultura alimentar local (RIBEIRO, 2007).

A feira de Alvorada de Minas concentra sua oferta em gêneros alimentícios, conforme caracterização feita por Mascarenhas e Dolzani (2008). Segundo Sacco dos Anjos et al. (2005), a despeito das novas pautas de consumo padronizadas, influenciadas pelos movimentos da globalização, e da grande disponibilidade e facilidade dos alimentos industrializados, os alimentos in natura, oferecidos na feira, uma vez que se associam aos valores artesanais, são reconhecidos como alimentos de qualidade única.

O julgamento sobre a qualidade dos produtos da feira é sempre positivo. Os produtos são adjetivados como bons, duráveis, de qualidade, saudáveis e, até mesmo, "abençoados", sendo considerados melhores e com mais variedade que os produtos do mercado. O preço também é considerado menor pela grande maioria dos consumidores entrevistados.

A aquisição de produtos sem o uso de agrotóxicos e a valorização da agricultura familiar vem aumentando e as características físicas de um produto alimentício já não são os atributos mais valorizados pelos consumidores contemporâneos, que têm sido fortemente influenciados pelos condicionantes que conferem a qualidade nutricional. A população brasileira está modificando seus hábitos alimentares e estimulando a busca por alimentos frescos, com origem e processos transparentes e que promovam a saúde (SILVA et al., 2013).

Os produtos da agroindústria familiar também estão presentes nas principais compras dos consumidores entrevistados - queijo, pão, doce, farinha, mel e biscoito - o que demonstra um consumo alimentar regionalizado, cultural, típico da região, distante do padrão industrial de alimentos presentes nos espaços de comercialização varejistas.

A confiança do consumidor no feirante é forte fator de decisão: confiam na qualidade daquilo que vem diretamente da roça para a banca. Além da confiança, existe uma espécie de solidariedade, pois há aqueles que compram sempre dos mesmos feirantes (confiança) e outros que procuram comprar um pouco de cada um, variando com o que cada um tem para oferecer, para dinamizar a venda de todos (solidariedade).

De acordo com Figueiredo et al. (2003), o mercado relativo às feiras tem as seguintes características: (i) mercado atomizado; (ii) a entrada/saída de feirantes não altera os preços praticados; (iii) preços são fixados de acordo com os concorrentes; (iv) preço recebido pelo produtor é igual ao pago pelo consumidor; (v) grande oscilação de preço entre o início e fim da feira; (vi) vendas feitas geralmente em dinheiro; (vii) volume comercializado pequeno; (viii) grande variedade de produtos; (ix) ocorre fidelização pela qualidade.

Nota-se, assim, a existência de um capital social baseado na confiança e na solidariedade, presentes em municípios de perfil rural, em que prevalece um ambiente de cooperação, com valores e intenções comuns. O capital social é entendido como um recurso para as pessoas e ele é produzido a partir de mudanças das relações entre as pessoas, que facilitam determinadas ações. Ele tem a ver com características da organização social como confiança, normas e sistemas, que contribuem para a eficiência da sociedade. A cooperação acontece para evitar riscos, mas efetivamente ela só se mantém pela interiorização de elementos morais pressupostos entre seus membros, daí é que surge a confiança (ABRAMOVAY, 2000).

\section{O COMERCIANTE}

Os comerciantes entrevistados foram divididos em dois grupos a partir de suas respostas: (1) aqueles que percebem aumento em suas vendas no dia da feira e (2) aqueles que não têm suas vendas afetadas pelo movimento criado por ela. Mais da metade dos comerciantes, entre mercearia, bar, padaria, loja de material de construção, loja de eletrodomésticos, avaliaram que há aumento no movimento do comércio local, tanto pelo público da feira quanto pelos próprios feirantes. Contudo, estes comerciantes não fazem cálculos de quanto, percentualmente, suas rendas aumentam em virtude desse movimento.

A boa relação entre a feira e o comércio entorno corrobora as afirmações de Morais e Araújo (2006), em suas análises da feira de Caicó (RN). As sociabilidades são tecidas pelas suas capacidades de

$\begin{array}{llllll}\text { Caminhos de Geografia } & \text { Uberlândia - MG } & \text { v. 19, n. } 68 & \text { Dez/2018 } & \text { p. 326-342 } & \text { Página } 337\end{array}$


estabelecerem laços com outros personagens, tramando concatenações e convivências harmoniosas. A interação entre a feira e o comércio local vai ao encontro também de Ribeiro (2007) que aponta as feiras como geradores de receitas que beneficiam os agricultores, o comércio urbano e os consumidores.

Os feirantes, durante as manhãs de sexta-feira, consomem no comércio local água, refrigerantes, sucos, pães, doces. Além disso, fazem suas compras, suprindo suas unidades familiares com bens manufaturados, como produtos de limpeza, material de construção em geral, eletrodomésticos, eletroeletrônicos, móveis e produtos cujo volume produzido (nas roças) não é suficiente, como o arroz e outros alimentos não perecíveis.

$\mathrm{Na}$ época em que as hortas ficam mais vistosas e suportam melhor as adversidades do tempo, a venda no comércio também melhora. Com o aumento na renda, os feirantes compram mais mercadorias, consumindo mais nos comércios locais. Isso demonstra que o consumo dos feirantes é variado, porém frequente. É muito comum a prática da venda "fiado" (quando se paga depois) para os feirantes, baseada na confiança e na palavra.

Mesmo para aqueles comerciantes que não têm suas vendas alteradas pelo movimento da feira, como em lojas de roupas, acessórios e esportivos, eles destacam a importância da mesma na oferta de alimentos saudáveis, "sem agrotóxicos e de qualidade", em que "entre a feira e o supermercado é melhor comprar na feira; não tem agrotóxico; vem da roça e bem mais em conta".

A importância da feira ganha visibilidade na medida em que se é destacada a qualidade e o caráter especial dos produtos. Para Braudel (2009), este tipo de mercado como a feira, se mantém pelo 'frescor dos gêneros perecíveis', pela venda sem intermediários, sendo a forma mais transparente de troca.

\section{CONSIDERAÇÕES FINAIS}

A incursão da Anglo American e a construção do maior mineroduto do mundo na região, em 2008, provocaram mudanças estruturais na agricultura familiar e a população de Alvorada de Minas vem sofrendo intensamente com a execução desta atividade. Os agricultores direta ou indiretamente impactados pelo empreendimento elaboram estratégias para minimizar os impactos da devastação ambiental e social sofrida pela prática da atividade minerária, como a extinção de cursos d'água, privatização de recursos naturais, o esvaziamento do campo, a violação de direitos e a desorganização dos modos de vida das famílias. Fica evidente que este grande projeto provocou perdas de referenciais espaciais, concretas, mas também simbólicas e culturais.

Contudo, as populações rurais brasileiras são marcadas pela busca da (re)construção de seus territórios, já que se esbarraram historicamente com a pressão sobre eles, pela luta contra a exploração e expropriação produzida no desenvolvimento do capitalismo. Essas lutas acontecem em detrimento do uso de seus territórios para projetos econômicos de envergadura como o projeto minerário abordado neste trabalho. Nesse sentido, as feiras-livres podem se configurar uma importante estratégia de (re)organização da vida das famílias agricultoras afetados pela mineração. As feiras asseguram renda e escoamento da produção campesina, sendo fundamentais como estratégias familiares. Apesar de competirem com o comércio varejista, elas persistem e resistem, o que indica que além dos aspectos econômicos, apresentam aspectos de outras naturezas, como a social e a cultural.

O objetivo desta pesquisa foi (re)conhecer a dinâmica de funcionamento da feira-livre existente em Alvorada de Minas, identificando sua importância enquanto espaço de comercialização da produção da agricultura familiar, mais especificamente para as famílias que sofrem os desmantelamentos provocados pela presença da mineração. A pesquisa buscou também conhecer a dinâmica da feira para que políticas públicas de desenvolvimento local/rural possam ser pensadas e implementadas no sentido de responder às demandas reais.

A feira-livre de Alvorada de Minas poderia representar uma alternativa para o fortalecimento da autonomia das famílias agricultoras que vê sua região destruída - enquanto natureza, relações sociais, culturais e econômicas - pela ação da mineradora. No entanto, ela ainda não está dinamizada. Diferentemente das feiras tradicionais e consolidadas, as feiras recentes não apresentam características de auto-gestão e sentimento latente de pertencimento ao lugar. Ao contrário, demandam suporte da prefeitura e das agências de assistência técnica quanto à estrutura, organização e divulgação, gerando dependência em relação a esses, dificultando a autonomia.

\begin{tabular}{llllll}
\hline Caminhos de Geografia & Uberlândia - MG & v. 19, n. 68 & Dez/2018 & p. 326-342 & Página 338
\end{tabular}


É importante ressaltar que os dados foram coletados em maio de 2016, representando a realidade daquele contexto. Em retorno ao município em outubro de 2017, fomos informados que a atual gestão do município não tem despendido os mesmos esforços para a manutenção e fortalecimento da feira. $\mathrm{O}$ apoio no transporte e na montagem das barracas foram afetados e a feira já apresenta sinais de desaparecimento. Nas regiões de implantação de grandes empreendimentos, não é raro que o poder público volte sua atenção às demandas a este setor, abandonando outros setores da sociedade. A agricultura familiar, que historicamente luta e resiste, com a chegada do empreendimento minerário se vê sujeitada a novos e grandes desafios de permanência no campo.

Com o enfraquecimento da feira muitos perdem: 1) os (as) agricultores (as) que deixam de se beneficiar com a venda de sua produção e que não entra em outros mercados, pois sua produção está atrelada à cultura alimentar local; 2) os comerciantes, já que os feirantes vendem para poder comprar no comércio aquilo que necessitam nas suas unidades familiares; 3) os consumidores, que deixam de ter um abastecimento regular de alimentos de qualidade, adaptado aos seus hábitos culturais. Esse enfraquecimento após a mudança de gestão mostra a importância da organização dos feirantes para lutarem por políticas públicas que lhes garantam o apoio do poder público, independente das alternâncias na administração da prefeitura. Reforça ainda a necessidade da gestão autônoma, tornando a feira um espaço dos agricultores e agricultoras que nela trabalham e dela extraem seu sustento.

A despeito de seu esmorecimento, a feira se mostrou como importante espaço na geração de renda tanto para os agricultores e agricultoras de Alvorada de Minas quanto para o comércio local, revelando a boa relação entre a feira e o comércio no entorno, pela sua capacidade de estabelecer laços de convivência e confiança. Ainda se faz presente a venda "fiado", relação com base na credibilidade e respeito entre as pessoas. A confiança também se faz presente na crença de que os alimentos disponíveis na feira são mais saudáveis. Essas características desvelam a sua importância enquanto espaço da agricultura familiar - de trocas comerciais e sociais e de resistência e fortalecimento das identidades rurais e de retomada de seus modos de vida.

Para evitar sua extinção, algumas estratégias podem ser desenvolvidas. $O$ acompanhamento das políticas de investimento dos governos estadual e nacional, que visam o fomento a este tipo de atividade, é relevante para o acesso e fortalecimento das políticas, e consequentemente do desenvolvimento rural. Visitas técnicas a outras feiras vizinhas (Conceição do Mato Dentro, Jequitinhonha, Itaponhacanga) podem servir como troca de experiências para que os feirantes permaneçam motivados e confiantes nos resultados que a feira pode proporcionar. Além disso, oficinas de sensibilização e valorização das feiras podem ser elaboradas pelos agentes de desenvolvimento local.

O escoamento da produção constitui um dos entraves ao desenvolvimento rural. Pretende-se reafirmar a importância da feira-livre, sua viabilidade como canal de comercialização da agricultura familiar e a necessidade de inseri-la na pauta de programas de desenvolvimento rural. $O$ fundamento apresentado é que a feira gera trabalho e renda no campo, dinamiza a economia local e garante a soberania e segurança alimentar para a população urbana, oferecendo alimentos frescos, produtos especiais e produtos com identidade local, além de ser espaço de ressignificação da economia local, dos aspectos socioculturais e identitários, já que é espaço privilegiado de organização e participação social, de trocas de conhecimentos e informações, processos fundamentais para a elaboração de estratégias de resistência em regiões atingidas por grandes empreendimentos.

São significativas as estratégias para resistir às mudanças impingidas às famílias agricultoras atingidas. As estratégias, pautadas na força da resistência, demonstram a capacidade de permanência que possuem e a busca por autonomia, que é uma luta permanente das populações rurais. Assim, reinventam-se, resistem, criam estratégias de reprodução e permanência no campo, que não são únicas, tampouco estáticas.

\section{AGRADECIMENTOS}

Agradecimentos à Cáritas Brasileira Regional Minas Gerais pelo apoio e financiamento desta pesquisa e aos agricultores e agricultoras de Alvorada de Minas. 


\section{REFERÊNCIAS}

ABRAMOVAY, R. Paradigmas do capitalismo agrário em questão. Campinas: Editora da Unicamp, 1992.

ABRAMOVAY, R. O capital social dos territórios: repensando o desenvolvimento rural. Economia Aplicada, v. 4, n. 2, p. 379-397, abril-jun/2000.

AGUILAR, A. Feira-livre: o consumo cultural na prática. Diário Popular, Pelotas, p. 7, 28 de março, 2004.

ANACLETO, A.; COELHO, A. P.; CURVELO, E. B. C. As mulheres empreendedoras e as feiras-livres no litoral do paraná. Faz Ciência, v. 18, n. 27, p. 118-139, jan-jun/2016.

ANGLO AMERICAN. Diálogo: publicação destinada às comunidades de relacionamento da Anglo American. Ano 1, n. 1, nov/dez, 2014. Disponível em:

$<$ http://brasil.angloamerican.com/ /media/Files/A/Anglo-American-Brazil-V3/reports-and-

presentations/minerio-de-ferro-brasil/dialogo-foos-nov-dez-2014.pdf> Acesso em: 25 fev. 2017.

ANGULO, J. L. G. Mercado local, produção familiar e desenvolvimento: estudo de caso da feira de Turmalina, Vale do Jequitinhonha, MG. Organizações Rurais e Agroindustriais, v. 5, n. 2, juldez/2003.

BARCELOS, E. O projeto minas rio e seus impactos socioambientais: olhares desde a perspectiva dos atingidos. Relatório Preliminar. Minas Gerais - Rio de Janeiro, 2013.

BELIK, W.; CUNHA, A. R. A. A.; COSTA, L. A. Crise dos alimentos e estratégias para a redução do desperdício no contexto de uma política de segurança alimentar e nutricional no Brasil. Planejamento e Políticas Públicas, n. 38, p. 107-132, jan-jun/2012.

BELLEZE, G. Comunidades rurais tradicionais atingidas pelo projeto de mineração Minas-Rio: Afinal, desenvolvimento para quem?. 2017. 141 f. Dissertação (Mestrado em Desenvolvimento, Tecnologias e Sociedade). Instituto de Engenharia de Produção e Gestão. Universidade Federal de Itajubá, Itajubá. 2017.

BORGES, D. C.; MASSAROLLO, M. D.; FAGUNDES, E. M.; CAMPOS, F. R. A importância da feira para produtor rural da agricultura familiar de Marmeleiro - PR. In.: V Congresso Nacional de Pesquisa em Ciências Sociais Aplicadas. 10, 2016. Anais..., Paraná, p. 1980-1983.

BRANDÃO, A. A.; NEVES, A. C.; CAVALCANTE, T. F. M.; ALVES, C. C.; CATÂO, H. C. R. M.; COSTA, A. C. Perfil socioeconômico dos consumidores de hortaliças em feiras-livres na microrregião de Januária no Norte de Minas Gerais. Horticultura Brasileira, v. 30, n. 2, p. 691-698, jul/2012.

BRAUDEL, F. $O$ jogo das trocas. Civilização material, economia e capitalismo: século XV-XVIII. São Paulo: Martins Fontes, 2009.

BUAINAN, A. M.; SOUZA FILHO, H. M. Agricultura familiar, Agroecologia e Desenvolvimento Sustentável: Questões para Debate. 1 ed. Brasília: IICA, 2006.

CARPEGEANI, C. B. F.; REZENDE FILHO, C. B. Caminho das Tropas: A Importância da preservação histórica e cultural como meio de preservação ambiental no Vale do Paraíba. Revista Ciências Humanas, v. 1, n. 1, p. [01-20], 2009.

CASSOL, A.; SALVATE, N.; SCHNEIDER, S. Mercados Imersos: uma perspectiva de análise institucional e relacional das trocas econômicas e do intercâmbio mercantil. Política \& Sociedade, v. 15, n. 33, mai/ago, 2016.

CONCEIÇÃO, C. A.; CARVALHO, M. M. X; COSTA, E. A. Canais de comercialização de alimentos dos camponeses dos assentamentos da fronteira Brasil-Bolívia. Caminhos de Geografia, v. 17, n. 60, p. 131-148, dez/2016.

FERRARI, D. L. Cadeias Agroalimentares Curtas: a Construção Social de Mercados de Qualidade pelos Agricultores Familiares em Santa Catarina. Tese (Doutorado em Desenvolvimento Rural). Faculdade de Ciências Econômicas. Universidade Federal do Rio Grande do Sul, Porto Alegre, 2011.

FIGUEIREDO, A. S.; PANTOJA, M. J.; MELO, M. F.; DIAS, R. L. Conhecendo seu canal de comercialização de hortaliças. Universidade Católica de Brasília, Empresa de Assistência Técnica e

$\begin{array}{llllll}\text { Caminhos de Geografia } & \text { Uberlândia - MG } & \text { v. 19, n. 68 } & \text { Dez/2018 } & \text { p. 326-342 } & \text { Página } 340\end{array}$


Extensão Rural e Conselho Nacional de Desenvolvimento Científico e Tecnológico. Brasília: Universa, 2003.

GABOARDI JÚNIOR, A. A importância da produção na agricultura familiar para segurança alimentar. In.: II Jornada Questão Agrária e Desenvolvimento: Projeto Sociais e Políticas Públicas em Disputa, 2, 2013. Curitiba, Universidade Federal do Paraná. Anais..., p. 1-12, 2013.

GODOY, W.; ANJOS, F. S. A importância das feiras-livres ecológicas: um espaço de Trocas e saberes da economia local. Rev. Bras. Agroecologia, v.2, n.1, p. 364-368, fev/2007.

GOMES JÚNIOR, N. N.; PIRES SILVA, R.; ALY JÚNIOR, O. Comercialização e segurança alimentar: buscando alternativas à exclusão. Cadernos do CEAM, v. 8, n. 31, p.113-132, 2008.

GUERREIRO, L. G. Resistências campesinas: La experiência de las Ferias Francas de la província de Missiones, Argentina. In: FERNANDES, B. M. Campesinato e Agronegócio na América Latina: a questão agrária atual. São Paulo: Expressão Popular, 2008. p.365-384.

IBGE. Instituto Brasileiro de Geografia e Estatística. Censo Demográfico. 2010.

IPHAN. Instituto do Patrimônio Histórico e Artístico Nacional. Inventário Nacional de Referências Culturais. Queijo artesanal de Minas: patrimônio cultural do Brasil. Dossiê Interpretativo. Belo Horizonte: maio de 2006.

LOVATTO, P. B.; ETGES, V. E.; KARNOPP, E. A natureza na percepção dos agricultores familiares do município de Santa Cruz do Sul, RS, Brasil: algumas perspectivas para o Desenvolvimento Regional Sustentável. Revista Redes, v.13, n. 1, p. 225-249, jan-abr/2008.

MARENGO, J. A.; NOBRE, C. A.; SELUCHI, M. E.; CUARTAS, A.; ALVES, L. M.; MENDIONDO, E. M.; OBREGÓN, G.; SAMPAIO, G. A seca e a crise hídrica de 2014-2015 em São Paulo. Revista USP, n. 106, p. 31-44, jul-set/2015.

MASCARENHAS, G; DOLZANI, M.C.S. Feira-livre: territorialidade popular e cultura na metrópole contemporânea. Revista Eletrônica Ateliê Geográfico, v. 2, n. 4, p.72-87, agosto/2008.

MORAIS, I. R. D; ARAÚJO, M. A. A. Territorialidades e Sociabilidades na Feira-Livre da Cidade de Caicó (RN). Revista Caminhos de Geografia, v. 23, n. 17, p. 244 - 249, fev/2006.

PAULINO, E. J.; DIAS, J. V. L.; MURTA, N. M. G.; MORAIS, H. A.; PIRES. H. H. R. A feira-livre de Couto de Magalhães de Minas, no Alto Vale do Jequitinhonha, Minas Gerais:a percepção dos feirantes e consumidores. Revista Desenvolvimento Social. Revista Desenvolvimento Social, $\mathrm{n}$. 20/1, p. 83-94, 2017.

PEREIRA, D. C.; BECKER, L. C.; WILDHAGEN, R. O. Comunidades atingidas por mineração e violação dos direitos humanos: cenários em Conceição do Mato Dentro. Revista Ética e Filosofia Política, v. 1, n. 16, jun/2013.

PEREIRA, V. G.; BRITO, T. P.; PEREIRA, S. B. A feira-livre como importante mercado para a agricultura familiar em Conceição do Mato Dentro (MG). Revista Ciências Humanas UNITAU v. 10, ed. 20, p. 67-78, dez/2017.

PEREIRA, V. G.; PIMENTA, C. A. M.; BELLEZE, G.; SILVA, G. C.; BATTISTON, K. M.; PEREIRA, S. B.; BRITO, T. P. Levantamento das potencialidades da agricultura familiar e agroecológica das comunidades rurais atingidas pela mineração nos municípios de Conceição do Mato Dentro, Alvorada de Minas e Dom Joaquim,MG. 180p. Relatório de pesquisa. Itajubá. 2016.

PLOEG, J. V. der. Camponeses e Impérios Alimentares: Lutas por autonomia e sustentabilidade na era da globalização. Editora UFRGS. Porto Alegre. 2008.

PLOEG, J. V. der. 0 modo de produção camponês revisitado. In: SCHNEIDER, Sergio (Org). A Diversidade da Agricultura Familiar. 2 ed. Porto Alegre: Editora da UFRGS, 2009.

PRA, M.; SABOURIN, E.; PETERSEN, P.; SILVEIRA, L. Lógicas e estratégias de comercialização na agricultura familiar do Agreste da Paraíba. Estudos Sociedade e Agricultura, v. 24, n. 1, p. 5-27, $\mathrm{abr} / 2016$.

RIBEIRO, E. M. (org.). Feiras do Jequitinhonha: mercados, cultura e trabalho de famílias rurais no semiárido de Minas Gerais. Fortaleza: Banco do Nordeste do Brasil, 2007. 
RIBEIRO, E. M; ÂNGULO, J. L. G.; NORONHA, A. B.; CASTRO, B. S.; GALIZONI, F. M. CALIXO, J. S. SILVESTRE, L. H. A feira e o trabalho rural no Alto Jequitinhonha: um estudo de caso em Turmalina, Minas Gerais. Unimontes Científica, v. 5, n. 1, p. 53-65, 2003.

RIBEIRO, E. M.; CASTRO, B. S.; SILVESTRE, L. H.; CALIXTO, J. S.; ARAÚJO, D. P.; GALIZONI, F. M.; AYRES, E. B. Programa de apoio às feiras e à agricultura familiar no Jequitinhonha mineiro. Agriculturas, v. 2, n. 2, jun/2005.

SACCO DOS ANJOS, F.; GODOY, W. I.; CALDAS, VELLEDA, N. As Feiras-livres de Pelotas sob o Império da Globalização: Perspectivas e Tendências. 1. ed. Pelotas: Editora e Gráfica Universitária, 2005.

SANTOS, M. V. Qualidade da água e qualidade do leite. Revista Mundo do Leite, p. 20-21, fevmar/2011.

SANTOS, M. S.; FERREIRA, D. J.; SANTOS, R. L. A feira-livre como alternativa de geração de renda para agricultura familiar no município de Santo Estevão - BA. In.: VI Congresso Iberoamericano de Estudios Territoriales y Ambientales, 6, 2014. São Paulo. Anais... São Paulo: 2014, p. 685-699.

SCHNEIDER, S.; FERRARI, D. L. Cadeias curtas, cooperação e produtos de qualidade na agricultura familiar: o Processo de Relocalização da Produção Agroalimentar em Santa Catarina. Organizações Rurais e Agroindustriais, v. 17, n. 1, p. 56-71, 2015.

SILVA, E. B.; CARDOSO, F. T.; SOUZA, G. G. ALMEIDA, A. Perfil sócio econômico de consumidores de produtos orgânicos. Revista Verde de Agroecologia e Desenvolvimento Sustentável, v.8, n. 1, p. 83-89, 2013.

VIEIRA, L. Ameaças e violações ao direito humano à água em Conceição do Mato Dentro e Alvorada de Minas, Minas Gerais. (Dossiê Denúncia). Minas Gerais, 2017, 50 p. Disponível em: < https://issuu.com/coletivomargaridaalves/docs/dossi_viola 2017. odireito gua > Acesso em: 08 out.

Recebido em: 24/12/2017

Aceito para publicação em: 06/11/2018 